\title{
Kurumsal Yerel Ăg Üzerinde Merkezi IP Telefon Santrali Kurulumu
}

\author{
Emre KARAKUŞa, ${ }^{\mathrm{a}}{ }^{*}$, Tuğrul TAŞÇI ${ }^{\mathrm{b}, 2}$, \\ a Sakarya Üniversitesi, Fen Bilimleri Enstitüsü, Bilişim Sistemleri Mühendisliği Bölümü, Sakarya, Türkiye \\ b Sakarya Üniversitesi, Bilgisayar ve Bilișim Bilimleri Fakültesi, Bilișim Sistemleri Mühendisliği Bölümü, Sakarya, Türkiye \\ İstanbul Sabahattin Zaim Üniversitesi Fen Bilimleri Enstitüsü Dergisi (2021) 3 (1): 51-55 \\ https://doi.org/10.47769/izufbed.864960 \\ (iD) ORCID ${ }_{1}^{1} 0000-0002-5580-2399 ;{ }^{2}$ 0000-0003-3820-6453;
}

\begin{tabular}{l}
\hline YAYIN BİLGİSI \\
\hline Yayın geçmişi: \\
Gönderilen tarih: 20 Ocak 2021 \\
Kabul tarihi: 06 Mart 2021 \\
\hline Anahtar kelimeler: \\
Asterisk \\
VoIP \\
SIP \\
IP Telefon Santrali \\
Kurum Ağları \\
\hline
\end{tabular}

\section{ÖZET}

Günümüzde çalışan sayısı yüksek olan birçok devlet kurumu ve özel sektör kuruluşu, çalışanları arasındaki iletişimi IP telefon santralleri üzerinden yürütmektedir. IP telefon santralleri, kurum ve kuruluşlara maliyet açısından orta ve uzun vadede avantajlar sunarken, bireyselleştirme seçenekleri ile kullanıcılar için esnek kullanım imkanları sağlamaktadır. Bu çalışmada, bir kamu üniversitesinin mevcut yerel kampüs internet ağ altyapısı üzerinde, IP telefon santralinin kurulum ve konfigürasyonu süreci ele alınmakta, gerekli teknolojik altyap1, donanım ve yazılımlara ilişkin bu süreçteki tasarım ve uygulama deneyimi paylaşılmaktadır. Çalışma, SIP protokolü, VoIP teknolojisi ve açık kaynak kodlu yazılımların kullanıldığı bir senaryo üzerinde gerçekleştirilmiştir. Çalışma sonucunda, 800 ila 1200 kullanıcı ek bir yazılım maliyeti olmaksızın birbirleriyle sesli ve görüntülü olarak görüşme imkanına sahip olmuştur.

\section{Installation of Central IP Telephone Exchange on Corporate Local Network}

\begin{tabular}{l}
\hline ARTICLE INFO \\
\hline Article history: \\
Received: 20 January 2021 \\
Accepted: 06 March 2021 \\
\hline Key words: \\
Asterisk \\
VoIP \\
SIP \\
IP Telephone Exchange \\
Corporate Networks
\end{tabular}

\begin{abstract}
Many govermental institutions and private sector companies having a large number of users today, provide communication between thier employees over IP telephone exchanges. While IP telephone exhanges offer mid and long term advantages in terms of maintenance and communication costs, they ensure flexible tenancy for users through individualization options. In this study, the installation and configuration process of an IP telephone exchange over the local area network of a state-owned university is presented and the experience regarding required technological infrastructure, hardware and software is shared.The study is implemented on a scenario in which SIP protocol, VoIP technology and open source software application are utilized. As a result of the study, 800 to 1200 users without any additional software cost get the opportunity to talk to each other with audio and video.
\end{abstract}

\section{Giriş}

İletişimin günlük hayatta en önemli ve vazgeçilmez gereksinimlerin birisi haline geldiği günümüzde, iletişim biçimleri de her geçen gün değişmekte ve çeşitlenmektedir. İletişim gelinen noktada, büyük ölçüde yerel ağlar ve Internet üzerinden sürdürülür duruma gelmiştir. Bireyler arasındaki kişisel ya da iş amaçlı görüşmelerin artık görüntülü ve sesli olarak ve aynı zamanda akıcı şekilde yapılabilmesinin sağlanması, bu hizmetleri sunan firmalardan temel düzeyde bir beklenti haline gelmiştir. Özellikle son bir yılda dünyanın karşı karşıya kaldığı Covid-19 pandemi süreci dolayısıyla da eğitim başta olmak üzere, birçok sektörde insanların yaşadıkları ortamdan katılımcı olma zorunlulukları iletişimin önemini bir kez daha ortaya koymuştur. Sürekli gelişim içinde bulunan iletişim teknolojileri, son yıllarda kurumlarda bu teknolojilere dayalı ürün ve hizmetlerin ortaya çıkmasını da beraberinde getirmiştir. Sektörde 
yaşanan hızlı gelişmelere bağlı olarak, gün geçtikçe daha çok uygulama ve platforma destek sunabilmesi, IP teknolojileri üzerinden ses ve video iletiminin de daha yüksek kalitede yapılabilmesi mümkün hale gelmiştir. $\mathrm{Bu}$ alandaki temel göstergelerden birisi olarak kabul edilen Global VoIP Marketi, 2015 yılında 83 milyar dolar iken 2021 yılında bu rakamın 140 milyar dolara olacağı öngörülmektedir (Anonim, 2020).

VoIP teknolojisine dayanan IP santrallerinin analog santrallere göre daha az maliyetli ve daha esnek çözümler sunması en başta gelen avantaj iken, açı kaynaklı sistemlerle birlikte çalı̧̧abilme yeteneği ile geliştirici ve kullanıcılar için kullanım, yönetim ve yazılım geliştirme alanlarında sunulan destekler de diğer önemli avantajlar arasında yer almaktadır.

IP santrallerinin başlıca avantajları şunlardır:

1- Büyük ölçekli kurumsal firmalar, üniversiteler, farklı lokasyonlarda birden fazla ofisi olan işletmeler ve bankalarda da oldukça yaygın kullanılmaktadırlar, ayrıca teknolojiye yatırım yapan büyük kurumların çoğunluğunda da tercih edilmektedir.

2- Geleneksel analog santrallere kıyasla IP santralleri, açık kaynak kodlu yazılımlarla geliştirilebilir olması, yönetiminin ve kullanımının kolay olması, çok düşük maliyetlere sahip olması, çok katılımcılı telekonferans görüşmesi desteği sunması, sanal ağlar üzerinden çalışması nedeniyle aynı anda hem internet hem de IP telefonların aynı hat üzerinden kullanılabilmesi, farklı lokasyonları olan işletmelere ücretsiz iletişim imkânı tanıması gibi çok sayıda avantajlara sahiptir.

3- Kullanıcılar masaüstü IP telefonlarından, cep telefonlarından, kişisel veya kurum bilgisayarlarından gerekli uygulamaları kullanmak kaydıyla geleneksel analog santrallerde desteklenmesi mümkün olmayan biçimde genişletilebilir kullanım alanları elde etmekte ve IP üzerinden iletişim kurulduğu için görüşme maliyeti çok düşük ya da ücretsiz olmaktadır.

IP santralleri için bir dizi teknolojinin farklı düzeylerde gerçeklendiği, iletilen görüntü ve ses kalitesinin farklı olduğu, kurulum, yapılandırma, raporlama ve yönetim için farklı yeteneklerde uygulama yazılımlarının sunulduğu çok sayıda profesyonel ürün ve hizmet bulunmakla birlikte, bütün bu işlemlerin açık kaynak kodlu yazılımlarla yapılabilmesi de mümkündür. $\mathrm{Bu}$ sayede, zaman içinde ortaya çıkan kurumsal ihtiyaçların ve kurum, departman ya da birey bazındaki özelleştirmeler için ek bir maliyete katlanmadan çözümler geliştirilebilmektedir.

Bu çalışmada, SIP protokolü, VoIP teknolojisi ve açık kaynak kodlu yazılımların birlikte kullanımına dayalı IP telefon santralleri ele alınmış olup, bir kamu üniversitesinin yerel kampüs ağ iç̧erisindeki ilgili yazılımların kurulum ve yapılandırma sürecindeki deneyimler paylaşılmıştır. Çalışmada, merkezi koordinasyon için Linux tabanlı Asterisk IP telefon santral sistemi kurulmuş olup, bu sistem üzerinden merkezi omurgaya dahil olan farklı binalardaki kullanıcıların, server-client mimarisi tabanlı iletişim altyapısı üzerinden sesli ve görüntülü olarak haberleşmeleri sağlanmıştır.

\section{IP Telefon Santralleri: Gelişim Süreci, Teknoloji ve Bileșenler}

\section{1 - Gelişim Süreci}

Telefon santralleri birden fazla telefonun birbirleriyle iletişim kurmasını sağlayan, ses ve görüntü iletişimi için aracılık eden ve genellikle kurumlarda kullanılan çok hatlı bir telefon sistemidir.
İngilizce Private Branch Exchange kelimelerinin baş harfleri olan PBX'in karşılığıdır (Van Meggelen ve Bryant, 2019). Dünya'da ilk telefon santrali 1878 yılında Amerika Connecticut'ta hizmete açılmıştır (Anonim, 2020b). Türkiye'de ise ilk manuel telefon santrali 1911 yılında İstanbul Kadıköy ve Beyoğlu ilçelerinde hizmete açılmıştır. Dünya'da ilk IP telefon santrali ise 1985 yılında Amerika - NSA(Ulusal Güvenlik Ajansı)'nda kullanılmaya başlanmıştır. Türkiye'de IP telefon santrallerinin kullanılması ise gerçek anlamda 2000'li yılların sonrasına dayanmaktadır.

IP telefon santralleri kurum içi haberleşmede tercih edilen, ağ üzerinden IP protokolü ile iletişim kuran yazılım tabanlı bir telekomünikasyon sistemidir. IP telefon santralleri ile kurum içerisindeki kullanıcılara kullanımı kolay ve sorunsuz bir iletişim olanağı sunulmaktadır. Kurumların iletişim maliyetlerinin düşürülmesinin yanı sıra yüksek kalite de ses ve görüntü transferi yapılabilmektedir. Günümüzde gelişen teknolojiyle beraber ă̆ tabanlı iletișim cihazları ile de kolaylıkla entegre olarak çalışabilmektedir.

Günümüzde birçok markanın ücretli IP telefon santralleri bulunmakta olup, ücretli ve ücretsiz olarak bu santraller ikiye ayrilmaktadır. LG Ericsson, Cisco Unified Call Manager, 3CX, Fortinet FortiVoice gibi markaların profesyonel çözümleri bulunmakla beraber, ücretsiz olarak Asterisk, Elastix, FreePBX, Kamailio gibi IP telefon santralleri bulunmaktadır.

Profesyonel çözümler; markaların kendilerine has fiziksel sunucuları, ücretli yazılım ve lisans maliyetlerinin bulunduğu sistemlerdir. Açık kaynak kodlu sistemler ise işletmenizde bulunan herhangi bir fiziksel veya mantıksal sunucu üzerine kurulan bir yap1 olduğundan dolayı tamamen ücretsizdir. Ücretli tarafta LG marka IP telefon santralleri IPECS protokolü, Cisco marka IP telefon santralleri SCCP ve SIP protokolü, 3 CX ve Fortinet FortiVoice marka IP telefon santralleri SIP protokolünü kullanırken, bu markalar kendi üretimi olan IP telefon cihazlarından farklı diğer marka ve model telefonları desteklememektedirler. Ücretsiz IP telefon santrali olan Asterisk, Elastix ve FreePBX gibi platformlarda ise SIP yazılımı kullanılmakta ve birçok IP telefon marka ve modellerini desteklemektedirler. Maliyet ve bireyselleștirme desteğini karşılama bakımından Asterisk açık kaynak bir proje olması sebebiyle işletmeler ve kurumlar için kullanışlı ve son zamanlarda oldukça popüler bir seçenek olarak ortaya çıkmıştır.

\section{2 - Teknoloji ve Güvenlik Hususları}

IP telefon santralleri VoIP, SIP, Routing gibi teknolojilerin ve bu teknolojiler temelinde işleyen uygulama yazılımlarının uygun şekilde yapılandırılarak bir araya gelmesiyle oluşturulmuş sistemlerdir. Bu kısımda, IP telefon santralleri için geçerli güncel teknolojiler, bu teknolojilere ilişkin potansiyel güvenlik açıkları ile bu çalışma kapsamında gerçeklenen IP santralinin altyapısında kullanılan donanım, yazılım ve yapılandırma ayarları ele alınmaktadır.

\subsection{1 - VoIP (Internet Protokolü Üzerinden Ses)}

Analog ses işaretlerinin sıkıştırılıp sayısallaştırılarak internet veya yerel ağlar üzerinden taşınabilmesini sağlayan bir teknolojidir. Sabit telefonlarda yalnızca bir görüşmenin yapıldığ hatlar üzerinden ses verileri asenkron veri akışı şeklinde ve düşük bir gecikmeyle gerçekleşmektedir. Buna karşıllık VoIP protokolünde veri ağlarında ilk önce ses sinyalleri büyük veri paketleri halinde şifrelenerek kodlanmakta, ardından küçük veri paketlerine parçalanmakta ve bunlar alıcı tarafinda tekrar bir araya getirilerek kodları çözülmektedir. Mantıksal olarak en basit şekilde VoIP, internet ağları üzerinden telefon görüşmesi yapmaktır (Madsen ve ark., 2007). VoIP'in kullanım nedenlerinden başlıcaları şunlardır: 
1. VoIP analog hatlara oranla daha ucuzdur çünkü sadece internet bilgisi dönüştürüldüğünde ücretlendirme yapılır.

2. VoIP hesabı almak (numara tahsis etmek) ücretsizdir. Coğrafi ve konumdan bağımsız numaralar VoIP altyapısı ile çağrı alabilir ve çağrı yapabilirler.

3. İnternet tabanlı olduğu için kullanılan servislere bağlı olarak uluslararası görüşmeler yapmanıza da imkan sağlar. Yani VoIP telefonunuza kurduğunuz uygulamalar ile dünyanın her yerinde aynı hesap kullanılabilir.

4. Ak1llı telefonlara yüklenen uygulamalar ile sabit numaralardan da çağrı alıp arama yapılabilir.

5. Analog hatlarda olmayan birçok ekstra farklı özellik kullanılabilir.

6. İnternet ağ altyapısını kullandığı için ilave ayrı bir altyapı ihtiyacina gerek duyulmaz.

\subsubsection{SIP (Oturum Başlatma Protokolü)}

Ses, video ve mesajlaşma uygulamalarını içeren gerçek zamanlı oturumları başlatmak, sürdürmek ve sonlandırmak için kullanılan bir sinyal protokolüdür. VoIP gibi IP üzerinden ses, görüntü ve anlık mesaj iletiminin yanı sira LTE (VoLTE) üzerinden cep telefonu araması için multimedya iletişim oturumlarını sinyalize etmek ve kontrol etmek için kullanılır. Günümüz IP telefonlarının çoğunluğu SIP Protokolü ile çalışmaktadır. SIP, IETF (Internet Mühendisliği Görev Gücü) tarafından geliştirilmiş düz bir metin protokolüdür ve OSI (Açık Sistem Ara bağlantısı) referans modeli 7. katman olan uygulama katmanında çalışır. IETF RFC 3261 standardı ile tanımlanmıştır. SIP esnek bir yapıya sahiptir. Esnek kelimesini daha da açmak gerekirse genişletilebilir, ölçeklendirilebilir, değişik mimari ve kurulum senaryolarına rahatça uyarlanabilir. Santral ortamındaki kullanıcılar yerel veya internet ağı üzerinden oturum açabilir, oturumun parametrelerini değiştirebilir ve oturumlarını sonlandırabilirler. Ses aktarımının yanı sıra aynı anda video ve veri aktarımı da sağlayan bir protokoldür. SIP verileri RTP (Real Time Protocol) (IETF RFC 3550) ile gerçek zamanlı taşınabilir (Johnston, 2009). SIP'in oturum başlatmak ve oturumu sonlandırmak için gerçekleştirdiği 5 farklı fonksiyonu vardır (Anonim, 2020c):

1. Kullanıcı konumunu belirlemek,

2. Bağlantıya katılacak kullanıcıları tespit etmek,

3. Uçların kapasitelerini tespit edip o şekilde medya parametrelerini ayarlamak,

4. Çağrı yapma ve iki uçtaki çağrı parametrelerini ayarlamak,

5. Oturumu yönetmek.

\subsubsection{Yönlendirme (Routing)}

Routing (yönlendirme), bir cihazdan alınan paketin ağ üzerinden farklı bir ağda bulunan diğer bir cihaza taşıyan protokoldür. Yönlendirme işleminin temelinde yönlendirici bulunur, yönlendirici birbirinden farklı ağlar ve tüm ağlara ulaşmak için kullanılabilecek en iyi yollar ile ilgilenirler ve bu sayede iletişim kurarlar (Karthikeyan, 2007). IP telefon santralinde ise yönlendiriciler kurum içerisindeki VoIP ile çalışan sistemlerin, analog ve GSM tabanlı sistemler ile iletişim kurmasını, T1/E1 ses arayüz kartlarıyla sağlayan dönüştürücü cihaz olarak görevlendirilirler.

\subsection{4 - VoIP ve SIP Güvenlik Açıkları}

IP telefon santrallerinde IP ağları üzerinden iletişim sağlanırken, alınan ses verilerinin küçük veri paketlerine ayrılarak karşı tarafa transfer edilmesiyle ağ saldırılarına açık bir teknoloji olduğu görülmektedir. Veriyi yok etme, çalma, engelleme ve değiştirme gibi bir çok saldırı tipine müsait bir teknolojidir. Bu saldırılar dışında Telekom sistemini çökertmek, sistemi kapatmak ya da sistemin kaynaklarının kullanımı gibi kaynak tabanlı saldırılar da gerçekleştirilebilir. VoIP uygulamasında güvenliği sağlamak için alınabilecek önlemlerden en önemlileri şunlardır:

1. Protokol sayesinde ses ve sinyal paketleri şifrelenmelidir. TLS(Taşıma Katmanı Güvenliği) ve SRTP(Güvenli Gerçek Zamanlı İletim Protokolü) ile gerçekleştirilebilir.

2. Güvenlik duvarı kullanılmalıdır.

3. VoIP sunucuları herhangi bir kaynak, Call Hijacking (Arama Araya Girme), MITM (Ortadaki Adam Saldırısı) saldırılarına karşın yedeklenmeli ve $\log$ (günlük kayıt) işlemlerinin düzgün bir şekilde ayarlanması gerekmektedir.

4. Yerel ağ üzerinde ses ve veri trafiğgi birbirinden soyutlanmış şekilde kullanılmalıdır.

5. Kullanıcı hesapları bazlı SIP hesapları oluşturulmalı ve farklı şifre kombinasyon teknikleri (MD5, SHA256) ile güvenliği sağlanmalıdır.

Protokollerin hiçbiri tek başına güvenliği sağlamak için yeterli değildir. Uygulanan güvenlik önlemleri seslerin iletilmesini yavaşlatabilir ve kullanıcı şikayetlerine sebep olabilir (Türkay ve ark., 2020)

\subsection{IP Santral Bileşenleri}

IP telefon santralleri, Pahalı ve geleneksel olan analog PBX santrallerinin dijitalleştirilip yazılımlaştırılmış halidir. Sayısal santraller ağlar üzerinde çalışan Linux temelli sunuculardan oluşur. $\mathrm{Bu}$ sayede iletişimi ağların üzerinden sağlar ve geleneksel santrallere göre maliyet olarak oldukça ekonomiktir. Sayısal santral kullanmanın en önemli avantajları; düşük maliyet, güvenlik, yönetim kolaylığı, kolay genişletilebilirlik ve geliştirilebilirliktir. Sayısal santral olarak Linux tabanlı, açık kaynak kodlu, ücretsiz ve geliştirilebilir olarak en çok kullanılan çözüm Asterisk'tir. Bu sisteminin diğer açık kaynak kodlu çözümlere oranla daha fazla tercih edilme nedenleri; sistem geliştiricileri için arka planda oldukça geniş bir teknik bilgi kaynağı bulunması, sistemin yazılım geliştirilmeye uygun olması ve bu çalışma çerçevesinde gerçeklenen uygulama için en uygun çözüm olarak değerlendirilmesidir.

\subsubsection{Asterisk}

Linux / Unix sistemler üzerinde sayısal santral çözümü olarak kullanılan bir açık kaynak kodlu bir yazılımdır. Mark Spencer adlı bir bilgisayar mühendisi tarafindan oluşturulmuş ve CTO'su olduğu Digium tarafından desteklenen bu IP PBX yazılımının kişisel ve ticari amaçlarla kullanımı ücretsizdir (Pepper, 2020). Asterisk'in açık kaynak kodlu bir yazılım olmasının avantajı olarak birçok özelliği de yanında getirmektedir. Analog santrallerden farklı olarak görüşme transferi, şef sekreter, çağrı yönlendirme, çağrı çekme, numara engelleme, birden çok çağrı alma ve görüşme yapma gibi işlemlerin yapılmasına olanak sağlar.

\subsubsection{VoIP PRI Geçit Yönlendiricisi}

Kurumların yerel ağ içerisinde kullandığı IP telefon santral sisteminin, kurum dışındaki analog ve GSM hatları arasındaki iletişimi kurmak ve Internet Servis Sağlayıcısı tarafından verilen önekler ile dış dünyadan gelen çağrıların işlenip kurum içerisindeki ilgili numaraya yönlendirme işlemleri için gerekli olan cihazdır (Anonim, 2020d)

\subsubsection{Omurga Anahtarlayıcı}

A $\breve{g}$ sistemleri üzerinde bulunan birden fazla anahtarlayıcının yükünün toplandığı veya ana yükün başladığı anahtarlayıcıya omurga anahtarlayıcı (backbone switch) denir. Ağın merkezinde bulunurlar. Omurga anahtarlayıcı birden fazla anahtarlayıcı cihaz 
arasında en fazla yükün bulunduğu birimdir. Tüm yükü toplar veya anahtarlayıcı cihazlar arasında yükü paylaştırır. Kurumların bütün veri ve ses trafiğgi Omurga anahtarlayıcı üzerinde sonlanır. Dış dünya ile iletişim omurga anahtarlayıcı üzerinden kurulur. Bütün sanal yerel alan ağları, erişim izinleri ve IP bloklarının genel konfigürasyonu omurga üzerinde yapılır (Wallingford, 2005).

\subsubsection{Kenar Anahtarlayıcılar}

Kenar anahtarlayıcılar iki ağın buluşma noktasında bulunan cihazlardır. Genellikle bilgisayar ve IP telefonların doğrudan bağlandığı cihazlardır. Sanal yerel alan ağlarını (VLAN) omurga anahtarlayıcıya bağlamakla görevlidir. Doğrudan kendilerine bağlı sistemlerin ihtiyacı olan anahtarlama ihtiyacını karşılayacak kapasitede olurlar. Kenar anahtarlarına erişim düğümleri veya hizmet düğümleri de denir (Anonim, 2020e).

\subsubsection{IP Telefon}

IP telefon geleneksel analog telefon ağları yerine IP protokolünü destekleyen her türlü hat üzerinden sesli ve görüntülü görüşme sağlayan, iletişimin düşük maliyetlerle sağlandığı VoIP sisteminin en önemli bileşenidir (Witowsky, 2020).

\section{Gerçeklenen IP Telefon Santrali Mimarisi ve Bileşenleri}

Kurumsal yerel ağlarda, IP telefon santrali şebekesi koordinasyonu oldukça çok zaman alan ve detaylı planlama isteyen bir sistemdir. Farklı sistemlerin kusursuz bir şekilde bir araya gelmesiyle oluşturulan bu yapı mantıksal ve fiziksel olarak çok iyi bir şekilde kurgulanmalıdır.

Koordinasyon için kesinlikle mevcut olması gereken VoIP (Asterisk) sunucusu, mevcut yerel ağa uygun bir şekilde konfigüre edilmeli, yerel ağdaki sistemlerin ilgili protokollerle uyumlu bir şekilde çalışması gerekmektedir. Yerel ağ içerisinde ana omurga ve kenar anahtarlayıcılar birbirleriyle son kullanıcıya iletişim hizmeti verecek bir şekilde uygun olarak yapılandırılmış olmalı ve IP telefon santrali sistemi bu yapıya uygun bir biçimde dahil edilmelidir. Ses iletimi için VoIP sunucusunun ve SIP protokolünün bant genişliği yüksek olmalı ve herhangi bir kıstlama veya engelleme yapılmamalıdır, ses verilerinin normal verilerden bağımsız olarak ayrı bir sanal ağ üzerinden aktarımı yapılmalı ve anahtarlayıcı cihazlar üzerinde ses verileri için gerekli olan QoS (Servis Kalitesi) konfigürasyonları yapılarak VoIP teknolojisine öncelik verilmelidir.

Sakarya Uygulamalı Bilimler Üniversitesi yerel kampüs ağ üzerinde gerçeklenen merkezi IP Telefon santrali için kurgulanan altyapı tasarımı Şekil 1.'de görülmektedir.

Yapının bileşenleri internet servis sağlayıcı tarafından verilen önekleri oluşturmak, analog ve GSM tabanlı sistemler ile iletişim kurulmasını sağlamak amacıyla VoIP PRI Gateway Router (VoIP PRI geçit yolu yönlendiricisi), yerel ağlarda ki ses ve internet verilerinin farklı VLAN'lardan iletimi ve merkezi bir VLAN yapılandırması oluşturmak için Omurga anahtarlayıcı, sisteme dahil olacak bütün IP telefonları tek bir merkezden yönetmek ve işletmek için gereken Linux tabanlı Asterisk IP telefon santral sunucusu, merkezi omurgada var olan sanal ağların, Asterisk IP telefon sunucusu ve IP telefonlar ile kesintisiz iletişimin sağlanması için kenar anahtarlayıcı ve son olarak IP telefonlardan oluşmaktadır. Bilgisayarlar ise IP telefonlarda entegre bir şekilde bulunan ikinci ethernet girişleri üzerinden ek bir maliyet oluşturmadan yerel ağa ve internet ağına bağlanabileceklerdir.

IP telefon santrallerinde ses verilerinin internet akış verileri ile karışmaması için kenar anahtarlayıcılar ile farklı sanal ağlarda ses ve internet verilerinin akışının belirlenmesi gerekmektedir. Bu sayede ses verileri ile internet verileri birbirlerine karışmayacaktır. Son kullanıcının kullandığı IP telefon fiziksel adresine göre Asterisk IP telefon santralinde 4 haneli sayısal bir numara atanarak hesap oluşturulması sonucu, sunucuda oturum açarak SIP protokolünün kullanımına ve VoIP üzerinden sesli iletişime hazır hale gelecektir.

Tüm bunların sonucunda kullanıma hazır hale gelen IP telefon, yerel ağ içerisindeki diğer IP telefonlarla ve diş dünyadaki aranabilir bütün telefon numaralarına ISP tarafından verilen gerekli önekler eklenerek iletişime geçebilecektir.

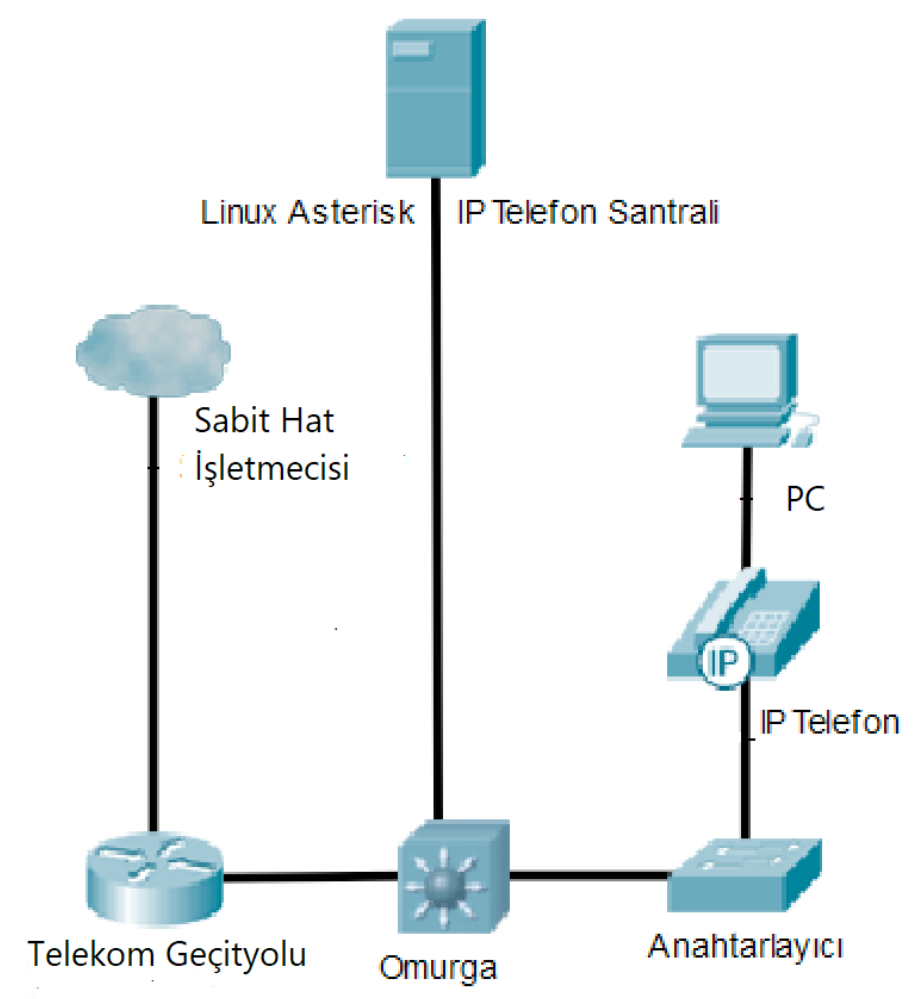

Şekil 1. Gerçeklenen Merkezi IP Telefon Santral Yapısı Fiziksel Şeması

Çalışma kapsamında gerçeklenen merkezi IP Telefon Santralinin mantıksal yapısı ve bu yapı üzerindeki veri akışı Şekil 2' de verilmiştir. Mantıksal işleyişte, "C-1" kod adı ile yapılan çağrı IP Telefon - 1'den dahili arama olduğu için sırasıyla IP Telefon - 1 cihazının bağlı bulunduğu Anahtarlayıcı - 1 ve Omurga cihazlarına sonrasında ise Asterisk IP Telefon Santraline ulaşmaktadır. Bu sayede Asterisk IP Telefon Santrali gelen çağrıyı kendi konfigürasyonuna bakarak Omurga ve Anahtarlayıcı - 2 cihazı üzerinden IP Telefon - 2 adlı cihaza ulaştıracaktır.

"C-2" Kod adı ile yapılan çağrıda ise IP Telefon - 2'den yapılan harici arama sirasıyla Anahtarlayıcı - 2 ve Omurga cihazlarına sonrasında ise Asterisk IP Telefon Santraline ulaşmaktadır. Asterisk IP Telefon Santrali gelen çağrıyı kendi konfigürasyonuna bakarak Omurga ve Telekom geçityolu üzerinden sabit hat işletmecilerine ulaştıracaktır. 


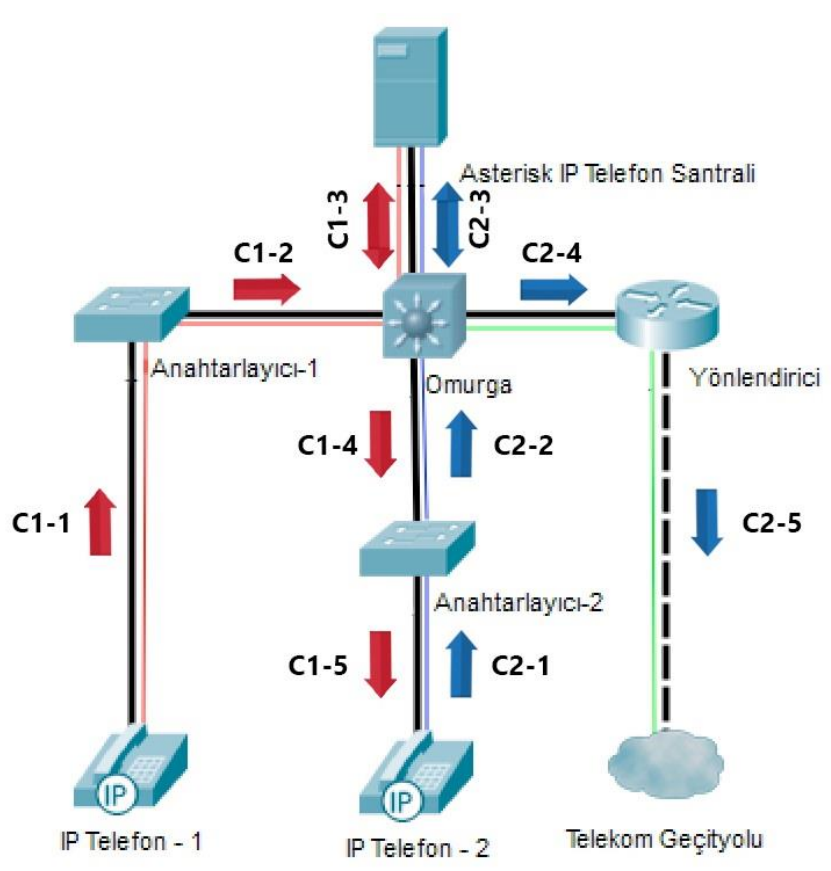

Şekil 2. Gerçeklenen Merkezi IP Telefon Santral Yapısının Mantıksal Şeması

\section{Bulgular ve Değerlendirme}

Bu çalı̧̧ma kapsamında Sakarya Uygulamalı Bilimler Üniversitesi (SUBÜ) yerel kampüs ağı üzerinde kurulan IP telefon santralinin kurulumu gerçeklenmiştir. Kurulum sırasında ve sonrasında fiziksel olarak IP telefonların sisteme dahil edilmesi ve gerekli ayarlamaların da yapılması sağlanmıştır. IP telefonlara uzaktan ve yerinde konfigürasyon aktarma işlemleri, yapılandırma işlemleri santral kurulumu kadar önemli bir yere sahiptir. Son kullanıcılara gerekli konfigürasyonlar yapıldıktan sonra yaklaşık iki yıllık bir süreç içerisinde sistem işleyişi üzerindeki rutin ve hata bazlı incelemeler donanımsal arıza durumları haricinde yazılımsal olarak büyük çaplı bir problem yaşanmamış olduğunu göstermiştir. Gerçeklenen sistem halen SUBÜ tarafından kullanılmaktadır.

SUBÜ'de mevcut 800 - 1200 kullanıcıya kurulan IP santralinin destek sağladığı ve aynı anda 400'ün üzerinde eşzamanlı çağrıyı yönetebildiği tespit edilmiştir. Kurulan sistemin işleyişi çeşitli raporlama ve yönetim komutları/yazılımları üzerinden izlenebilmektedir. Sistem üzerinden o anda görüşme halinde olan, aktif durumda olan ya toplam kullanıcı sayıları ile tarih, katılımcılar ve süre gibi çağrılara ilişkin detaylı bilgiler raporlanabilmektedir. Covid-19 pandemi dolayısıyla esnek çalışma sisteminin geçerli olduğu an itibariyle sunucu sistemi üzerinden anlık 32 adet aktif kanalın üzerinden 16 adet aktif çağrı görüşmesi olduğu raporlanmıştır. Sistem'de 2 yıllık süre içerisinde toplamda 490000'in üzerinde aktif çağrı sunucu tarafından işlenmiş bulunmaktadır.

\section{Sonuç}

$\mathrm{Bu}$ çalışmada, sesli-görüntülü görüşmeler için kurumlar tarafından günümüzde yaygın olarak tercih edilen IP santrallerin tarihi gelişimi, bu santrallerin temelinde kullanılan teknolojiler ve bunların güvenliğine dair hususlar ile IP santral kurulumu için gerekli donanım ve yazılımlar hakkında bilgi verilmiştir. Çalışmada; ayrıca bir kamu üniversitesinin yerel kampüs ağı üzerinde açık kaynak tabanlı uygulama yazılımları ile bir IP santrali kurulum, yapılandırma ve yönetim süreci açıklanmıştır.

Öncelikle IP telefon santrali için tercih edilen Linux tabanlı Asterisk sistemi için bir sunucu kurulumu yapılarak sonrasında bu sunucudaki ilgili servislerin SUBÜ ağına özel olarak yapılandırılması sağlanmıştır. Dış hatlar için VoIP PRI Geçit Yönlendiricisi, Internet Servis Sağlayıcısı ile yerel ağın iletişimini sağlayacak şekilde yapılandırılmış, omurga ve kenar anahtarlayıcı cihazlar üzerinden de kullanıcı IP telefonları ile santral sunucusu arasında iletişim için gerekli yapılandırmalar yapılmıştır. Kurulan ve yapılandırılan sistem, rutin ve hata tabanlı olarak iki yıla yakın bir süre gözlenmiş ve donanım kaynaklı arızalar dışında iletişim sürecini yöneten uygulama yazılımına ilişkin kritik bir arızaya rastlanmadığı tespit edilmiştir. Sistem halen SUBÜ kullanıcılarına başarılı şekilde hizmet vermeye devam etmektedir.

Yapılan çalışmadaki kurulum ve yapılandırma bir kurum ile sınırlı olduğundan aynı teknoloji, donanım ve yazılımlar tercih edilse bile farklı ağ altyapıları ve kurumsal ihtiyaçlar için farklı yapılandırma ayarları gerekecektir. Uygun fizibilite ve altyapı çalışmaları yapıldığında farklı kurumların birbirleriyle IP ağları üzerinden noktadan noktaya ücretsiz görüşme sağlayabilmeleri ve bu sayede iletişim maliyetlerini oldukça düşük bir seviyeye çekebilmeleri de mümkündür.

\section{KAYNAKLAR}

Anonim (2020). So Dou You Depend On VoIP Phone Service? Erişim tarihi: 2020,10. "https://www.voipphonetips.com/\#axzz6eKhjgsOD"

Anonim (2020d). VoIP PRI Gateways. Erişim tarihi: 2020,10. "https://www.voip-info.org/voip-pri-gateways"

Anonim (2020e). Edge device. Erişim tarihi:2020,10. "https://en.wikipedia.org/wiki/Edge_device"

Anonim, (2020b). History of the Telephone. Erişim Tarihi: 2020,10 .

"https://en.wikipedia.org/wiki/History_of_the_telephone"

Anonim, (2020c). SIP. "Erişim tarihi: 2020,10" "https://tr.wikipedia.org/wiki/SIP"

Erişim tarihi: 2020,10. "https://ab.org.tr/ab15/bildiri/227.odt"

Johnston, A.B. (2009). "Understanding the Session Initiation Protocol", Artech House Telecommunications.

Karthikeyan. D.M. (2007). Network Routing: Algorithms, Protocols, and Architectures.

Madsen, L. Jared Smith ve Jim Van Meggelen. (2007). Asterisk: the future of telephony. "O'Reilly Media, Inc."

Pepper. R. 2020. What is Asterisk?. Erişim tarihi: 2020,09 "https://getvoip.com/library/what-is-asterisk/"

Ted Wallingford, T. (2005). "Switching to VOIP”, O'Reilly Media Inc.

Türkay, E., Hamdi Burak Dilek, Hüseyin Erkan Çetinkaya, Enis Karaaslan. 2020. Kurumsal Yazilım Telefonu Prototipi Geliştirme Süreci.

Van Meggelen, J, Russell Bryant. (2019). Asterisk: The Definitive Guide, 5th Edition.

Witowsky. W.E. 2020. IP Telephone Design and Implementation Issues. Erişim tarihi: 2020,10.“https://www.ti.com/pdfs/vf/bband/ip_telephone.pdf 